\title{
Consumer survey of a mental health resource centre
}

\author{
Kate SaCkett, Registrar in Psychiatry and Femi Oyebode, Consultant Psychiatrist, The \\ John Conolly Hospital, Birmingham
}

The first British day hospital was established by Bierer in $1946 ;^{1}$ by the end of the 1950 s there were 45 and during the next few years the number trebled. ${ }^{2}$ With the trend towards community care, day hospitals and centres have continued to increase in number.

The style, philosophy and programmes offered by day centres differ considerably and the composition of clientele also varies. ${ }^{3}$ In line with the developments in community care, day care off hospital sites has been advocated. ${ }^{4}$ Day care is therefore being combined with other facilities such as out-patient clinics, crisis intervention or walk-in service, or as bases for community psychiatric nurses and clinical psychologists. In this way the modern day hospital has adopted something of the nature of the community mental health centre in the USA. Recent examples described in the UK include Lewisham Mental Health Advice Centre, Tameside and Brindle House. $^{2}$ This British version of the community mental health centre can be and has been called "community mental health resource centre".

We wish to describe briefly Stratford Road Day Centre (SRDC), which is in our view a prototype of a community mental health resource centre, and report the findings of a recent survey of the opinion of patients on various aspects of the functioning of the centre.

Stratford Road Day Centre (SRDC) is a terraced house in Sparkhill, Birmingham. It is situated in a high density, high immigrant part of the city, along a busy road, miles from its parent hospital. The centre is identifiable only by its house number, and thus is not clearly set apart as a psychiatric facility. The whole spectrum of psychiatric disorders (i.e. major psychoses, neuroses and personality disorders) are seen in the centre. There are several treatment programmes offered, including an Asian men's group, an Asian women's group, a social club, a three-day psychotherapy group, two out-patient psychotherapy groups, an art therapy group for psychotic patients, weekly community meetings, a schizophrenia relatives' support group, and a drop-in service. In addition, depot neuroleptic, lithium, and daily out-patient clinics are held. The centre is a base for the Asian Language Service, which provides a domiciliary and out-patient service for Asian patients.
The clinical team comprises nurses, community psychiatric nurses, an art therapist, social workers and doctors. There is no occupational therapist or clinical psychologist input.

The office space is modest. There are two group rooms, labelled by colour or size rather than by ownership; three rooms suitable for interviews with individuals, a small room used as a treatment room, a general office and kitchen. There is little separation of staff and patient facilities and no separation of patients by psychiatric diagnoses or facility used. The centre fits the description of a hospital with minimal "social distance", "block treatment", or "depersonalisation", as defined by Shepherd \& Richardson."

A questionnaire researching the views of the consumers of the service provided by Stratford Road Day Centre was distributed to all patients attending the centre in the one week beginning 13 July 1987 , requiring respondents to declare whether they were satisfied or not with 13 aspects of the service. Eight of these factors were considered by Tyrer \& Remington $^{6}$, in their report on day care in Southampton. These factors were: ease of access, appointment times, time spent with staff, waiting time, knowledge about treatment offered, continuity of care, atmosphere of the centre, and staff understanding of patients' problems. To these we added frequency of attendance, external and internal appearance of the rooms, condition of the rooms, and communication between the different staff involved in the management of the patients. These additional factors were enquired into in order to evaluate the consumers' opinion about the appropriateness of the regularity of sessional appointments, anonymity of the building, non-clinical appearance of the rooms, general decorative condition of the rooms and finally perception by the patients of the quality of staff communication.

We were aware that the patients could be inclined to give positive responses and tried to reduce this possibility by ensuring that the evaluative procedure was divorced from therapy session. In order to establish some hallmark to compare the responses against, members of staff also completed a similar questionnaire.

One hundred and eight patients used the centre in the study week, of whom $72(67 \%)$ completed and returned the research questionnaire. 
There were $36(50 \%)$ males, $35(48.6 \%)$ females, and one patient who did not respond to the enquiry into gender. The majority of respondents $(62.5 \%)$ were aged between 25 and 55 years. The control group was composed of 13 staff members, a response rate of $92.9 \%$.

The majority of patients were satisfied with each item on the questionnaire. There was, however, a marked discrepancy between the views of patients and staff on four items: the decorative condition of rooms, the general atmosphere in the centre, the continuity of care provided to patients, and the quality of communication amongst staff about patients (Table I).

TABLE I

Questionnaire responses

\begin{tabular}{|c|c|c|}
\hline \multirow[b]{2}{*}{ Factor } & \multicolumn{2}{|c|}{ Percentage of respondents satisfiea } \\
\hline & Patients & Staff \\
\hline & $\%$ & $\%$ \\
\hline Ease of access & 76 & 85 \\
\hline Frequency of attendance & 79 & 62 \\
\hline Outside appearance & 86 & 92 \\
\hline Inside appearance & 81 & 77 \\
\hline Conditions of rooms & 85 & 15 \\
\hline Waiting time before first & & \\
\hline appointment & 82 & 69 \\
\hline Waiting time before each & & \\
\hline attendance & 82 & 92 \\
\hline Knowledge of treatment & 74 & 69 \\
\hline Atmosphere & 85 & 54 \\
\hline Time spent with staff & 83 & 69 \\
\hline Staff understanding & 79 & 77 \\
\hline Continuity of care & 83 & 38 \\
\hline Communication & & \\
\hline between staff & 89 & 38 \\
\hline
\end{tabular}

Our findings suggest that there is general satisfaction amongst patients with the location, appearance, atmosphere and style of the centre. Some of the comments made by patients in the questionnaire reveal much about their attitudes to the centre and to psychiatry in general:

"SRDC art therapy group should be a model for future groups, indeed the idea of community care in 'households' such as SRDC must be continued." "I would like a staff member to see relatives and wife once a week." "I feel strongly about the houselike environment, professional but unhospital-like." "I am p-off with the staff, they don't give a f$s-$ about us. They do not understand us and they do not want to." "Doctors don't know how to ftreat me. They would rather I just went ahead and try and commit suicide again and succeed."

The items on which the staff opinions differed from the patients are interesting. The staff were dissatisfied with the decorative state of the rooms, the atmos- phere of the centre, the continuity of care provided and the quality of communication amongst staff about patients. It is easy to explain the difference in opinion about the decorative state of the rooms because staff remain in the building longer and are therefore more likely to be affected by it. In addition, it may be that the staff have an idealised vision of what the centre should look like. The dissatisfaction with the other items is more difficult to explain. In our view, it probably reflects tensions within the multi-disciplinary team system. It is intriguing that the patients do not seem to perceive or be adversely influenced by the dissatisfaction of the staff with these areas.

In our view, our findings have demonstrated that a small, locally based centre providing the full range of psychiatric care with the exception of in-patient treatment is acceptable to patients. The features of the centre which increase its acceptability to patients such as ease of access, anonymity, non-clinical appearance of rooms, and its informal atmosphere, may not necessarily be looked upon favourably either by staff or planners. In a period of diminishing financial resources, there are problems with the idea of planning a centre for each locality. In addition, although the informal atmosphere of the centre may reduce the anxiety of patients, it could easily limit the efficiency of medical assessment.

We concede that there are problems inherent in the model that we describe but argue that these do not do serious damage to the model.

\section{Acknowledgement}

We wish to thank our colleagues, Anne Bennett, Helen Greenwood, Michael Radford, Trevor Rigg, Monica Samuels and Bernice Williams for their cooperation. Thakor Mistry, Veenu Luxmi and Yasmin Qureshi assisted in translating the questionnaire. Mrs M. Baker gave secretarial assistance.

\section{References}

${ }^{1}$ Vaughan, P. J. (1985) Developments in psychiatric day care. British Journal of Psychiatry, 147, 1-4.

${ }^{2}$ Martin, F. M. (1984) Between the Acts, Community Mental Health Services 1959-1983. Nuffield Provincial Hospitals Trust.

${ }^{3}$ EdITORIAL (1985) Day hospitals for psychiatric care. Lancet, 2, 1106-1107.

${ }^{4}$ ROBERTSON, J. A. (1985) Community psychiatry and its discontents. International Journal of Social Psychiatry, 31, 176-188.

SSHEPHERD, G. \& Richardson, A. (1979) Organisations and interactions in psychiatric day centres. Psychological Medicine, 9, 573-579.

${ }^{6}$ Tyrer, P. J. \& Remington, M. (1979) Day hospitals and controlled comparison of out-patient treatment for neurotic disorders. Lancet, 1, 1014-1016. 